\title{
Test of the RUSLE and Key Influencing Factors Using GIS and Probability Methods: A Case Study in Nanling National Nature Reserve, South China
}

\author{
Jun Wang $\mathbb{D}^{1,2}$ Qian He, ${ }^{3}$ Ping Zhou $\mathbb{C}^{1,2}$ and Qinghua Gong ${ }^{1,2}$ \\ ${ }^{1}$ Guangdong Open Laboratory of Geospatial Information Technology and Application, Guangzhou 510070, China \\ ${ }^{2}$ Guangzhou Institute of Geography, Guangzhou 510070, China \\ ${ }^{3}$ College of Foresting and Landscape Architecture, South China Agriculture University, Guangzhou 510642, China
}

Correspondence should be addressed to Ping Zhou; pzhou@gdas.ac.cn

Received 30 May 2019; Accepted 1 October 2019; Published 11 November 2019

Academic Editor: Salvatore Grasso

Copyright (c) 2019 Jun Wang et al. This is an open access article distributed under the Creative Commons Attribution License, which permits unrestricted use, distribution, and reproduction in any medium, provided the original work is properly cited.

\begin{abstract}
The main purposes of the study were to test the performance of the Revised Universal Soil Loss Equation (RUSLE) and to understand the key factors responsible for generating soil erosion in the Nanling National Nature Reserve (NNNR), South China, where soil erosion has become a very serious ecological and environmental problem. By combining the RUSLE and geographic information system (GIS) data, we first produced a map of soil erosion risk at $30 \mathrm{~m}$-resolution pixel level with predicted factors. We then used consecutive Landsat 8 satellite images to obtain the spatial distribution of four types of soil erosion and carried out ground truth checking of the RUSLE. On this basis, we innovatively developed a probability model to explore the relationship between four types of soil erosion and the key influencing factors, identify high erosion area, and analyze the reason for the differences derived from the RUSLE. The results showed that the overall accuracy of image interpretation was acceptable, which could be used to represent the currently actual spatial distribution of soil erosion. Ground truth checking indicated some differences between the spatial distribution and class of soil erosion derived from the RUSLE and the actual situation. The performance of the RUSLE was unsatisfactory, producing differences and even some errors when used to estimate the ecological risks posed by soil erosion within the NNNR. We finally produced a probability table revealing the degree of influence of each factor on different types of soil erosion and quantitatively elucidated the reason for generating these differences. We suggested that soil erosion type and the key influencing factors should be identified prior to soil erosion risk assessment in a region.
\end{abstract}

\section{Introduction}

Soil erosion is a vital environmental issue around the world leading to the destruction of soil resources, the decline of soil fertility, the deterioration of the ecological environment, and the elevation of riverbeds to exacerbate floods [1-4]. As for South China, the area of soil erosion is reported about $300,000 \mathrm{~km}^{2}$, which is mainly distributed in the mountainous or hilly areas of red soil, of which the soil erosion rate can reach $15,000 \mathrm{t} \cdot \mathrm{km}^{-2} \cdot \mathrm{yr}^{-1}$ [5]. Soil erosion in this area, especially accelerated soil erosion induced by human activities, is extremely severe, and it has tremendous socioeconomic impact. Thus, South China has long been an important region for soil erosion research.
There are many methods to assess soil erosion at varying scales [6-9]. The Revised Universal Soil Loss Equation (RUSLE) is the most widely used empirical model because of its simple, transparent, robust model structure and compatibility with geospatial platforms $[10,11]$. Recently, many studies have reported to predict soil erosion by combining the RUSLE and geographic information system (GIS) [1217]. For example, Fayas et al. [18] evaluated the maximum average annual soil erosion of $103.7 \mathrm{t} \cdot \mathrm{ha}^{-1} \cdot \mathrm{yr}^{-1}$ in the Kelani River watershed in Sri Lanka. Panagos et al. [19] evaluated the mean soil loss rate was $2.46 \mathrm{t} \cdot \mathrm{ha}^{-1} \cdot \mathrm{yr}^{-1}$ in erosion-prone areas of the European Union. Zerihun et al. [20] classified NW Ethiopia into five soil erosion severity classes and estimated the total soil loss of $526.996 \mathrm{t} \cdot \mathrm{ha}^{-1} \cdot \mathrm{yr}^{-1}$. Review of 
these studies reveals most have focused on quantitative assessments of soil loss, while few have considered the ground truth checking of the RUSLE and underlying key influencing factors of soil erosion.

Application of a soil erosion model alone in a region might produce many large differences when addressing localized erosion problems. This is because average rates of soil loss might be within tolerable limits, while the problem could be locally severe, i.e., the erosion model might underestimate the erosion risk in some land cover units within a watershed. Therefore, ground truth checking is extremely important and it must be performed after application of the predicted model. The main factors affecting soil erosion are climate, topography, soil, vegetation, geology, and human activities $[21,22]$. The RUSLE depends only on five factors, i.e., rainfall erosivity $(R)$, soil erodibility $(K)$, slope length and steepness $(L S)$, cover management $(C)$, and support practice $(P)$; thus, there is potential for neglect of some other more important elements that influence local soil erosion, such as slope pattern, lithology, and distance to drainage networks. For different watersheds, the key factors responsible for generating soil erosion are obviously very different. Wu and Wang [23] studied the relationship between soil erosion and influencing factors in Fuyang County, China, and found that soil erosion exhibited high selectivity of geographical factors, such as elevation, slope, aspect, and land use. Ma et al. [24] found that the impact of land use pattern on soil erosion distribution had become increasingly important and suggested that more attention should be paid to the role of adjustment and optimization of land use structure in soil erosion control. Bohm and Gerold [25] confirmed the important role of vegetation in soil erosion, and they found a small effect of the soil texture and slope. Li and Tang [26] found that human activity was a very important factor in the lower reaches of the Jinsha River, China. Sachs and Sarah [27] highlighted that soil erosion was strongly influenced by soil type, slope rate, and vegetation type and coverage. Wang et al. [28] quantitatively tested the relationship between overall soil erosion and environment factors in the Nanling National Nature Reserve, China, and found that the soil erosion is mainly distributed in a specific range of environmental factors, such as 500-1300 m elevation, red and scrubby-meadow soil, and $>40$ slope. However, they did not further discuss the relationship between different types of soil erosion (rill erosion, sheet erosion, gully erosion, and human-induced erosion) and environmental factors. Meanwhile, they did not estimate total annual potential soil loss by the RUSLE model and thus not test the application of RUSLE in NNNR. Therefore, prior to erosion modelling, it is essential not only to establish the land cover units that have high erosion rates but also to determine the underlying influencing factors of soil erosion.

The overall objectives of this study were to assess soil erosion risks by combining RUSLE, GIS, and RS, to test the performance of the RUSLE, and to understand the key factors responsible for generating soil erosion. The specific objectives were as follows: (i) to derive the spatial distribution and type of soil erosion from RS and field measurement techniques, (ii) to map a soil erosion risk by integration of the RUSLE and GIS, (iii) to test the performance of the RUSLE by ground truth checking, and (iv) to understand the key factors responsible for generating soil erosion and the reasons for the differences derived from the RUSLE using GIS and the developed probability method. To achieve these objectives, the Nanling National Nature Reserve (NNNR), located in northern Guangdong Province, South China, was selected as the study area. Because of the complex function of natural and artificial factors, this area suffers from many environmental problems such as soil erosion, land resources destruction, soil fertility declination, and deterioration of the ecological environment.

\section{Materials and Methodology}

2.1. Characterization of the Study Area. The Nanling National Nature Reserve (NNNR), was chosen as the case site (Figure 1), covers an area of $583.68 \mathrm{~km}^{2}$ in northern Guangdong Province, South China. Lithologically, granitic rocks are widespread in the Nanling region, especially the Jurassic granitoid has the widest area. The topography is complex and controlled by the east-west mountain structure, with an elevation ranging from $202.1 \mathrm{~m}$ to $1902 \mathrm{~m}$. The seismic acceleration in the study area is $0.05 \mathrm{~g}$. The slope angle ranges from $0.0^{\circ}$ to $64.3^{\circ}$ with an average of $19.5^{\circ}$. The water system is dendritic and can be roughly divided into five levels (Figure 1). From east to west, there are two main river basins: Nanshui River and Chengjia River. The area has a distinct vertical zonality of four major soil orders (red soil, red-yellow soil, yellow soil, and shrub meadow soil). Vegetation ranges from subtropical evergreen broad-leaved forests to alpine meadows. Currently, the forest coverage is above $90 \%$.

The study area has a climate of subtropical monsoon. Multiyear average annual temperature is nearly $17.7^{\circ} \mathrm{C}$. Multiyear average precipitation ranges from 1452.1 to $2154.5 \mathrm{~mm}$ (Figure 2(a)). The frequency distribution of average monthly precipitation is shown in Figure 2(b), from which we can see that June has the most precipitation, December has the least precipitation, and approximately $70 \%$ of rainfall is from March to July.

The spatial distribution of different types of soil erosion in NNNR can be obtained by interpreting the remote sensing image. The type of soil erosion in NNNR can be roughly classified into four classes: rill erosion, sheet erosion, gully erosion, and human-induced erosion, which can be seen in Figure 3, from which we can find that the different types of soil erosion have obvious differences in distribution characteristics and influence environmental factors in NNNR. To reduce soil erosion and its affects to ecological environment within the NNNR, it is very important and urgently needed to obtain the spatial distribution of soil erosion, identify the risks caused by the soil erosion, and determine the key factors that control different types of soil erosion.

2.2. Research Methodology. The flow chart of the study is shown in Figure 4. There are three main parts in our study, that is, soil erosion estimation by RUSLE, ground truth checking of the RUSLE, and analysis of the key influencing factors of soil erosion. The details are as follows. 


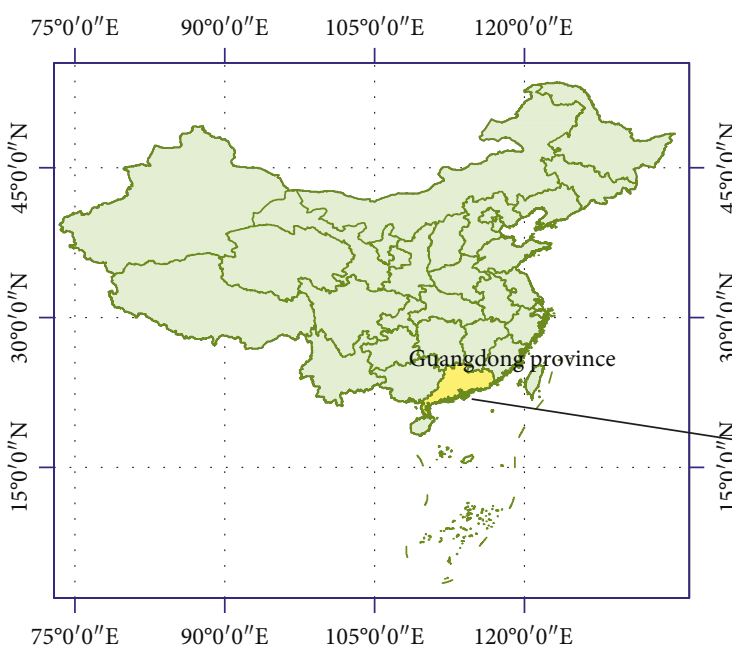

(a)
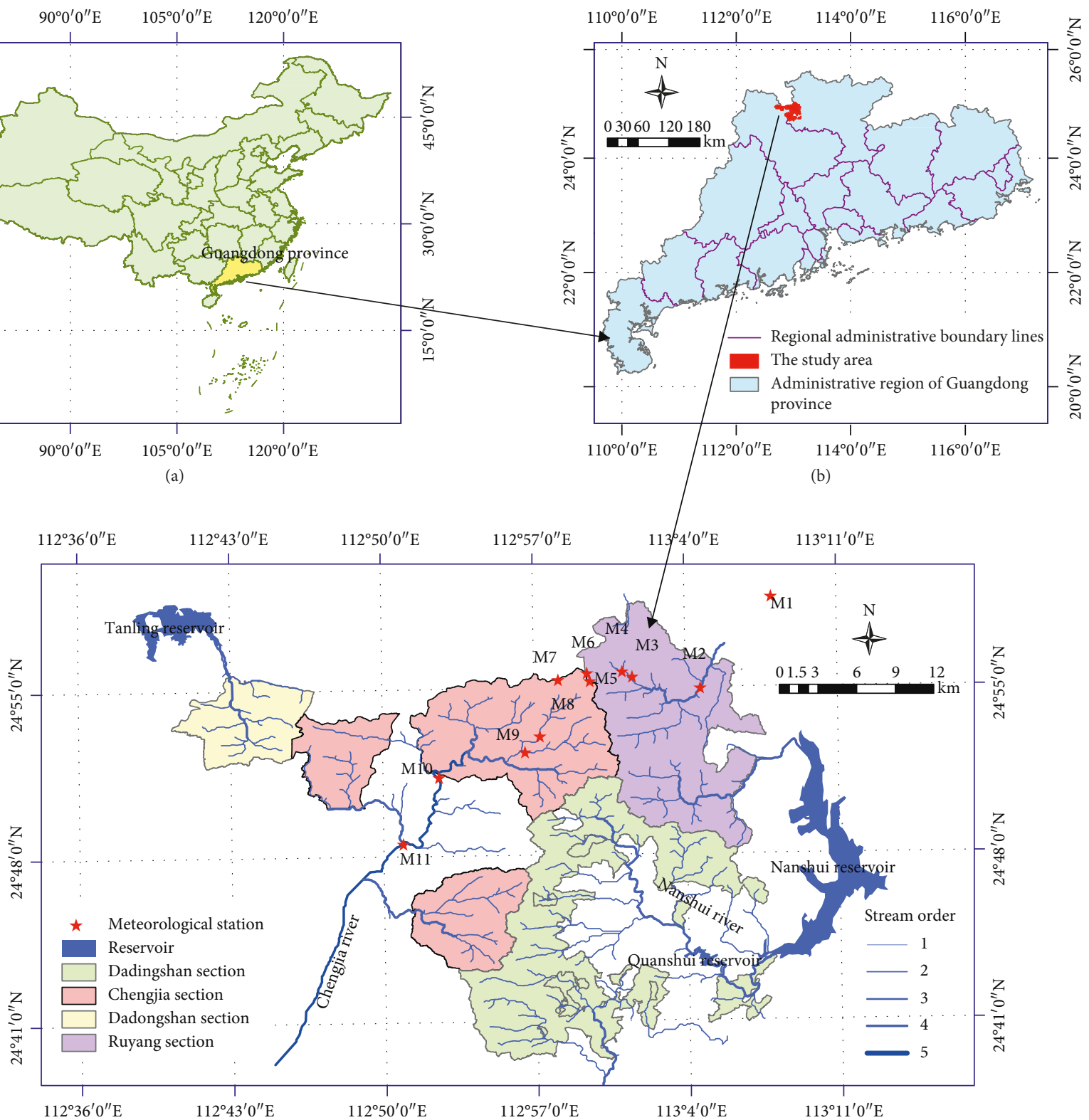

(c)

FIgURE 1: Location of the study area: (a) inset map showing the location of Guangdong Province in China, (b) inset map showing the location of the study area in Guangdong Province, and (c) map of the study area with stream order and four major sections. Figure 1 is reproduced from Wang et al. [28] (under the Creative Commons Attribution License/public domain).

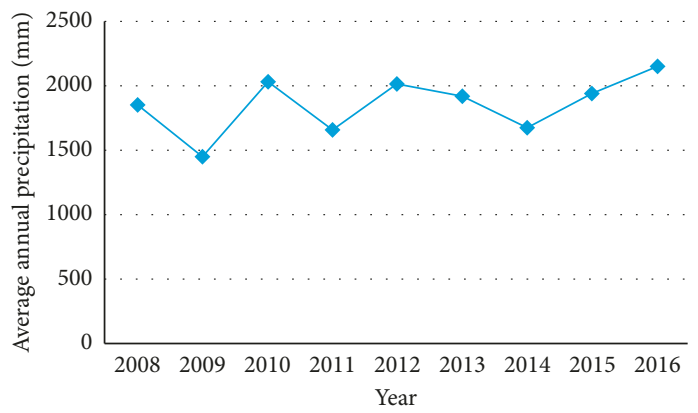

(a)

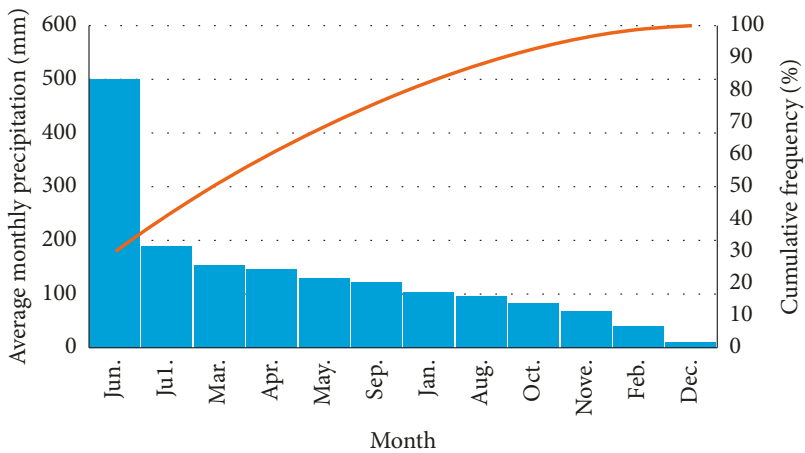

(b)

FIGURE 2: Multiyear average precipitation from 2008 to 2016 (a) and frequency distribution of average monthly precipitation (b) of 11 meteorological stations in NNNR. 


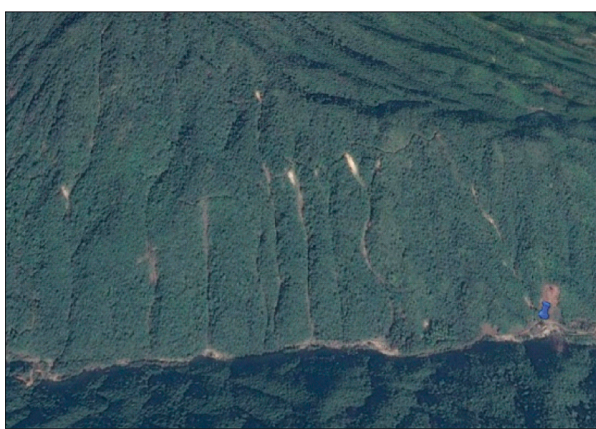

(a)

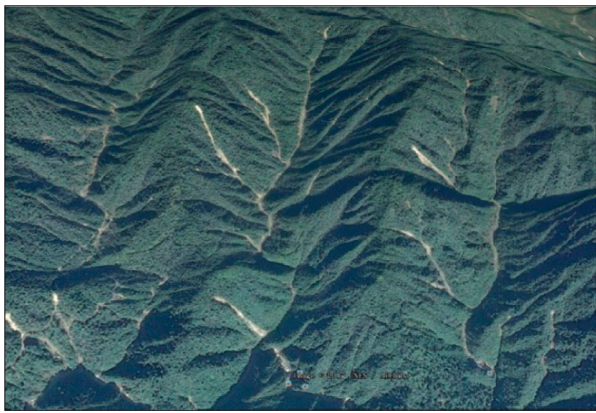

(c)

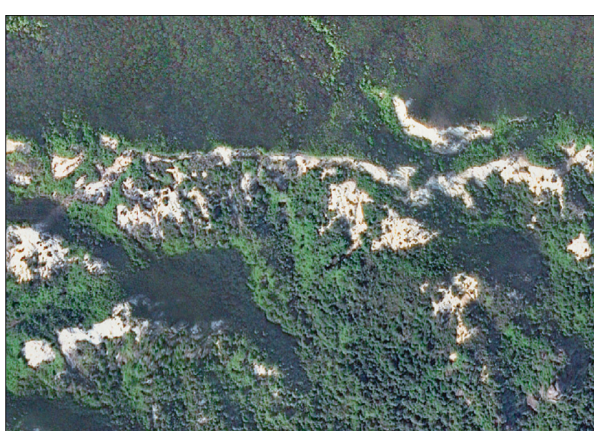

(b)

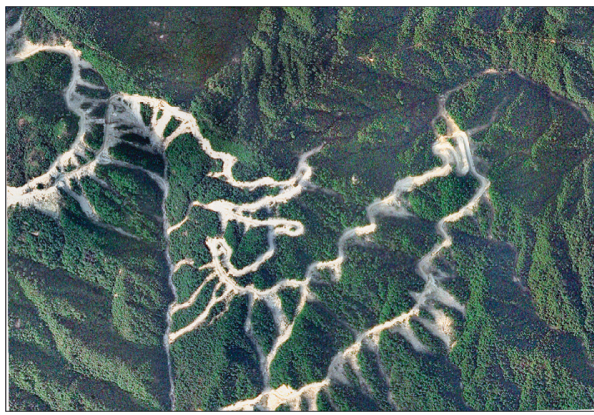

(d)

Figure 3: The soil erosion types of NNNR: (a) rill erosion along a slope, (b) sheet erosion mainly along mountain ridge lines, (c) gully erosion along the gully, and (d) human-induced erosion. The green colour in each photo is the vegetation cover.

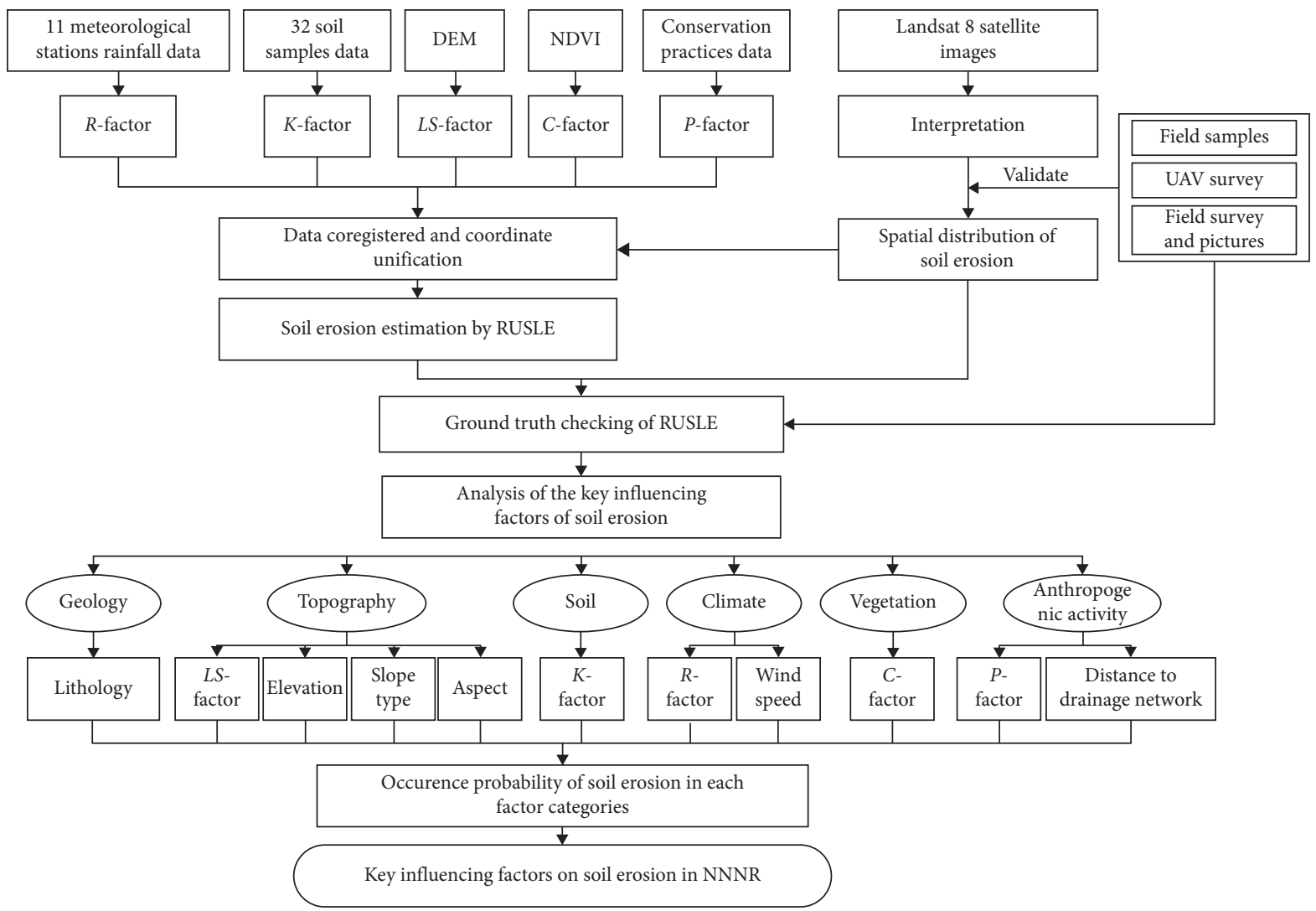

Figure 4: The methodology used in the study. 
2.2.1. Soil Loss Estimation by RUSLE. The RUSLE model, which was used in this study to predict the soil loss and to identify the erosion-prone areas, can be expressed as $[20,29,30]$

$$
A=R \times K \times L S \times C \times P,
$$

where $A$ is the annual soil loss ( $\left.\mathrm{t} \mathrm{ha} \cdot \mathrm{yr}^{-1}\right), R$ is the rainfall erosivity factor $\left(\mathrm{MJ} \mathrm{mm} \cdot \mathrm{ha}^{-1} \cdot \mathrm{h}^{-1} \cdot \mathrm{yr}^{-1}\right), \mathrm{K}$ is the soil erodibility factor ( $\mathrm{t}$ ha $\mathrm{h} \cdot \mathrm{ha}^{-1} \cdot \mathrm{MJ}^{-1} \cdot \mathrm{mm}^{-1}$ ), $\mathrm{L}$ is the slope length factor (contributing area), $S$ is the slope steepness factor, $C$ is the cover and management practice factor, and $P$ is the erosion control practice factor. The rainfall data are mainly the daily rainfall data of the 11 rainfall stations in the study area from 2008 to 2016. Soil data are mainly for collecting soil samples in the field. The terrain data are mainly Digital Elevation Model (DEM). The cover and management practice and erosion control practice data are mainly derived from remote sensing images and field survey data. These data were used to generate the RUSLE model input factors in equation (1), and the detailed calculation method is as follows.

$R$-factor is an index of rainfall erosivity that quantifies the potential capacity of rain to cause erosion. Many researchers have devoted establishing several simplified models between rainfall erosivity and daily/monthly/annual rainfall [31-34]. Wang et al. [35] proposed an equation of $R$ factor in Lianjiang basin in northern Guangdong Province based on monthly rainfall by using the 35 meteorological stations from 1980 to 2013, which is shown as follows:

$$
R=0.0125 \times P_{m}^{1.6295} \times 17.2,
$$

where $R$ is the rainfall erosivity factor $\left(\mathrm{MJ} \mathrm{mm} \cdot \mathrm{ha}^{-1} \cdot \mathrm{h}^{-1} \cdot \mathrm{yr}^{-1}\right.$ ) and $P_{\mathrm{m}}$ is the monthly rainfall $(\mathrm{mm})$. The current research location is very close to that of the study location by Wang et al. [35], so those two climatic conditions are similar. It is therefore used to calculate the $R$-factor of the study area. The rainfall data of the 11 rainfall stations in the study area from 2008 to 2016 were collected to estimate $R$-factor in NNNR. Then, the spatially distributed map of $R$-factor can be generated by using the calculated $R$-factor and meteorological stations in ArcGIS.

Soil erodibility ( $K$-factor) indicates the soil erosion sensitivity to rainfall and runoff detachment, which is an inherent property of the soil. It is also closely related to soil texture, structure, organic matter content, hydraulic properties, and wettability [36-38]. This study used EPIC (Erosion Productivity Impact Calculator) model proposed by Williams et al. [39] to calculate $K$-factor in NNNR:

$$
\begin{aligned}
K=\left\{0.2+0.3 \exp \left[-0.0256 m_{\mathrm{s}}\left(1-\frac{m_{\text {silt }}}{100}\right)\right]\right\}\left(\frac{m_{\text {silt }}}{m_{\mathrm{c}}+m_{\text {silt }}}\right)^{0.3} \\
\\
\cdot\left[1-\frac{0.25 \operatorname{org} C}{\operatorname{org} C+\exp (3.72-2.95 \mathrm{org} C)}\right] \\
\\
\cdot\left[1-\frac{0.7\left(1-m_{\mathrm{s}} / 100\right)}{\left(1-m_{\mathrm{s}} / 100\right)+\exp \left[-5.51+22.95\left(1-m_{s} / 100\right)\right]}\right]
\end{aligned}
$$

where $K$ is the soil erodibility factor in $\mathrm{t} \mathrm{ha} \mathrm{h} \cdot \mathrm{ha}^{-1} \cdot \mathrm{MJ}^{-1} \cdot \mathrm{mm}^{-1}$, orgC is \% organic matter, $m_{\mathrm{s}}$ is \% sand $(0.05-2.0 \mathrm{~mm}$ size fraction), $m_{\text {silt }}$ is $\%$ silt $\left(0.002-0.05 \mathrm{~mm}\right.$ size fraction), and $m_{\mathrm{c}}$ is \% clay ( $<0.002 \mathrm{~mm}$ size fraction). 32 soil samples were collected to determine the soil properties of NNNR. The sampling position should be chosen such that the soil sample can represent a different gradient distribution in the NNNR. In the laboratory, soil samples were passed through a $2 \mathrm{~mm}$ screen and soil properties were tested using the standard procedures. After calculating the $K$-factor of the soil sample in NNNR, a continuous $K$-factor grid surface was generated by spatial interpolation technique in ArcGIS.

The dimensionless $L S$-factor represents the effect of terrain on soil erosion and is the product of the slope length factor $(L)$ and the slope steepness factor $(S)$. In this study, the combined $L S$-factor was calculated as the following equation using the DEM in ArcGIS 10.1 [40]:

$$
\begin{aligned}
& L=\left(\frac{\lambda}{22.1}\right)^{m}, \\
& S= \begin{cases}10.8 \sin \theta+0.03, & \theta<5^{\circ}, \\
16.8 \sin \theta-0.5, & 5 \leq \theta<10^{\circ}, \\
21.91 \sin \theta-0.96, & \theta \geq 10^{\circ},\end{cases}
\end{aligned}
$$

where $L$ is the slope length factor, $S$ is the slope steepness factor, $\lambda$ is the slope length extracted from DEM, $m$ is the slope length and slope steepness index, and $\theta$ is the slope.

The $C$-factor has been used to reflect the impact of vegetation cover and management practices on the soil erosion rate. The related scholars used different spectral vegetation indices and the fraction images from spectral mixture analysis of remotely sensed images to compute the $C$-factor [36, 41, 42]. In our study, the mean of NDVI generated from Landsat 8 images was used to calculate the $C$ factor by using the equation proposed by Ostovari et al. [16]:

$$
C=\exp \left[-\alpha \times \frac{\mathrm{NDVI}}{\beta-\mathrm{NDVI}}\right],
$$

where $\alpha$ and $\beta$ are the parameters defining the shape of the NDVI-C curve, and an $\alpha$ value of 2 and a $\beta$ value of 1 provide reasonable results.

The $P$-factor reflects the impact of conservation support practice to the soil loss rate [43-45]. Because the study area has high vegetation coverage and very little arable land that has no special conservation practices, the $P$-factor of the NNNR is set as 1 .

To make the spatial data of different sources have the same coordinate system so as to improve the accuracy of data processing and superposition, each vector and raster layer must be coregistered to a common geographical coordinate. In this study, the reference of Universal Transverse Mercator system (UTM): WGS_1984_UTM_Zone_49N, was used to rectify and georeference each data. After generation of all the RUSLE factors (i.e., $R$-factor, $K$-factor, $L S$ factor, $C$-factor, and $P$-factor), the output of annual soil loss was calculated using a pixel-by-pixel method in ArcGIS 10.1. 
2.2.2. Ground Truth Checking of the RUSLE. A Landsat 8 satellite image (no. LC81230432015106LGN00) taken on August 15, 2015, was used to estimate the spatial distributions of soil erosion in the study area, which was also rectified and georeferenced to the same reference of WGS_1984_UTM_Zone_49N. The overall spatial distribution of soil erosion was first estimated by using the Support Vector Machine Supervised Classification of the ENVI 5.1 platform based on the remote sensing image characteristics. Then, the distributions of four types of soil erosion were further subdivided based on the RS spectral characteristics, terrain slope, and geometric shape. Finally, the interpreted results were validated by the intensive fieldwork. Fieldworks were undertaken several times in 2016, 2017, 2018, and 2019. Field investigations and sampling were conducted along the contour line within walking distance. For different types of soil erosion, representative sample locations were identified and their geographic coordinates were recorded using a global positioning system receiver. These locations were later used as samples (in total 32 samples) to assess image classification accuracy. For very important but inaccessible areas of erosion in the NNNR, we used an unmanned aerial vehicle (UAV) to survey the soil erosion for the verification of the interpreted results (in total five UAV samples). More than 4000 field pictures were also taken for visual verification of the interpreted results. After verification of the interpreted result, the ground truth checking of the RUSLE can be carried out for assessing the performance of the RUSLE in its application to the NNNR by using spatial overlay analysis function in ArcGIS 10.1.

\subsubsection{Analysis of the Key Influencing Factors of Soil Erosion.} After ground truth checking, the differences between the RUSLE results and the actual situation can be obtained. In order to find out the reason for the differences between the RUSLE results and the actual situation, the underlying key influencing factor must be determined first. Generally, the extent and magnitude of soil erosion are determined by its key geoecological factors, such as climate, topography, soil, vegetation, geology, and human activities. Thus, the following six categories of 10 variables which closely related to local soil erosion are selected: geology (lithology), topography (LSfactor, elevation, slope type, and aspect), soil ( $K$-factor), climate ( $R$-factor and 10-min maximum wind speed), vegetation ( $C$-factor), and anthropogenic activity (distance to the drainage network). Here, a probability method was developed as follows [28]:

$$
\mathrm{CF}_{i}= \begin{cases}\frac{P_{a i}-P_{\mathrm{s}}}{P_{a i}\left(1-P_{\mathrm{s}}\right)}, & \text { if } P_{a i} \geq P_{\mathrm{s}}, \\ \frac{P_{a i}-P_{\mathrm{S}}}{P_{\mathrm{s}}\left(1-P_{a i}\right)}, & \text { if } P_{a i}<P_{\mathrm{s}},\end{cases}
$$

where $\mathrm{CF}_{i}$ is the certainty coefficient of the $i$-th data class, $P_{a i}$ is the conditional probability of soil erosion in data class $i, P_{\mathrm{s}}$ is the a priori probability of soil erosion in the study area (constant), and $i$ is the number of the data class in a factor, $i=1,2, \ldots, n$. The value of $P_{a i}$ can be calculated as

$$
P_{a i}=\frac{a_{i}}{A_{i}},
$$

where $a_{i}$ is the area of soil erosion in data class $i$ and $A_{i}$ is the area of data class $i$. The value of $P_{s}$ can be calculated as

$$
P_{\mathrm{S}}=\frac{s_{i}}{S_{i}}
$$

where $s_{i}$ is the area of soil erosion in the study area, which is equal to the area of the interpreted results of soil erosion; here, $S_{i}$ is the area of the NNNR.

Each factor was first classified into several data classes according to its special attributes. Then, the area of soil erosion in each data class and the area of each data class were calculated using zonal statistics methods in ArcGIS. Finally, the values of $P_{s}, P_{a i}$, and $\mathrm{CF}_{i}$ were calculated using equations (8), (7), and (6), respectively. The calculated certainty coefficient $\mathrm{CF}$ value ranges from -1 to 1 . When the CF value is close to 1 , the certainty of soil erosion is great and soil erosion is likely to occur [28]. Conversely, when the CF value is close to -1 , the certainty of soil erosion is low and soil erosion is less likely to occur. According to the calculated CF value of each data class, the probability of soil erosion in each data class could be obtained. The maximum CF value of all data classes in a factor was defined as the CF value of this factor; thus, the probability of soil erosion in each factor, key underlying influencing factors of soil erosion, and areas of high risk of erosion within the NNNR could be obtained.

\section{Results and Discussion}

3.1. Calculated Result of the RUSLE Model. The spatial distribution maps of the RULSE result and its input variables are shown in Figure 5. The detailed results are described as follows: The average monthly rainfall data of 11 meteorological stations in NNNR (Figure 1) used to compute the rainfall erosivity factor ( $R$-factor) by equation (2) are listed in Table 1 and Figure 5(b). The $R$-factor value was between 8181.52 and $14621.56 \mathrm{MJ} \mathrm{mm} \cdot \mathrm{ha}^{-1} \cdot \mathrm{h}^{-1} \cdot \mathrm{yr}^{-1}$. The average of $R$-factor was 12131.28 MJ mm $\cdot \mathrm{ha}^{-1} \cdot \mathrm{h}^{-1} \cdot \mathrm{yr}^{-1}$. The maximum and minimum values of the $R$-factor appeared in 2009 and 2010, respectively. The $R$-factor from May to August had relative high value in a year. Meanwhile, a strong significant linear positive correlation was found between $R$-factor and elevation in the study area.

The soil characteristics and soil erodibility $K$-factor in NNNR are given in Table 2 and Figure 5(c), from which we could observe that the value of $K$-factor was ranging from 0.1456 to $0.2384 \mathrm{t}$ ha $\mathrm{h} \cdot \mathrm{ha}^{-1} \cdot \mathrm{MJ}^{-1} \cdot \mathrm{mm}^{-1}$, with an average value of $0.1714 \mathrm{t}$ ha $\mathrm{h} \cdot \mathrm{ha}^{-1} \cdot \mathrm{MJ}^{-1} \cdot \mathrm{mm}^{-1}$. In further analysis, it was found that the $K$-factor in this region had a strong correlation with $\% m_{s}(r=-0.74)$ and $\% m_{\text {silt }}(r=+0.68)$ and less correlation with $\% m_{c}$ and $\% \operatorname{org} C$.

The calculated $L S$-factor in NNNR is listed in Table 3 and Figure 5(d). The minimum and maximum values of $L S$ factors were 0 and 612.105, respectively. The low $L S$-factor value is mainly distributed along the river valley, especially 

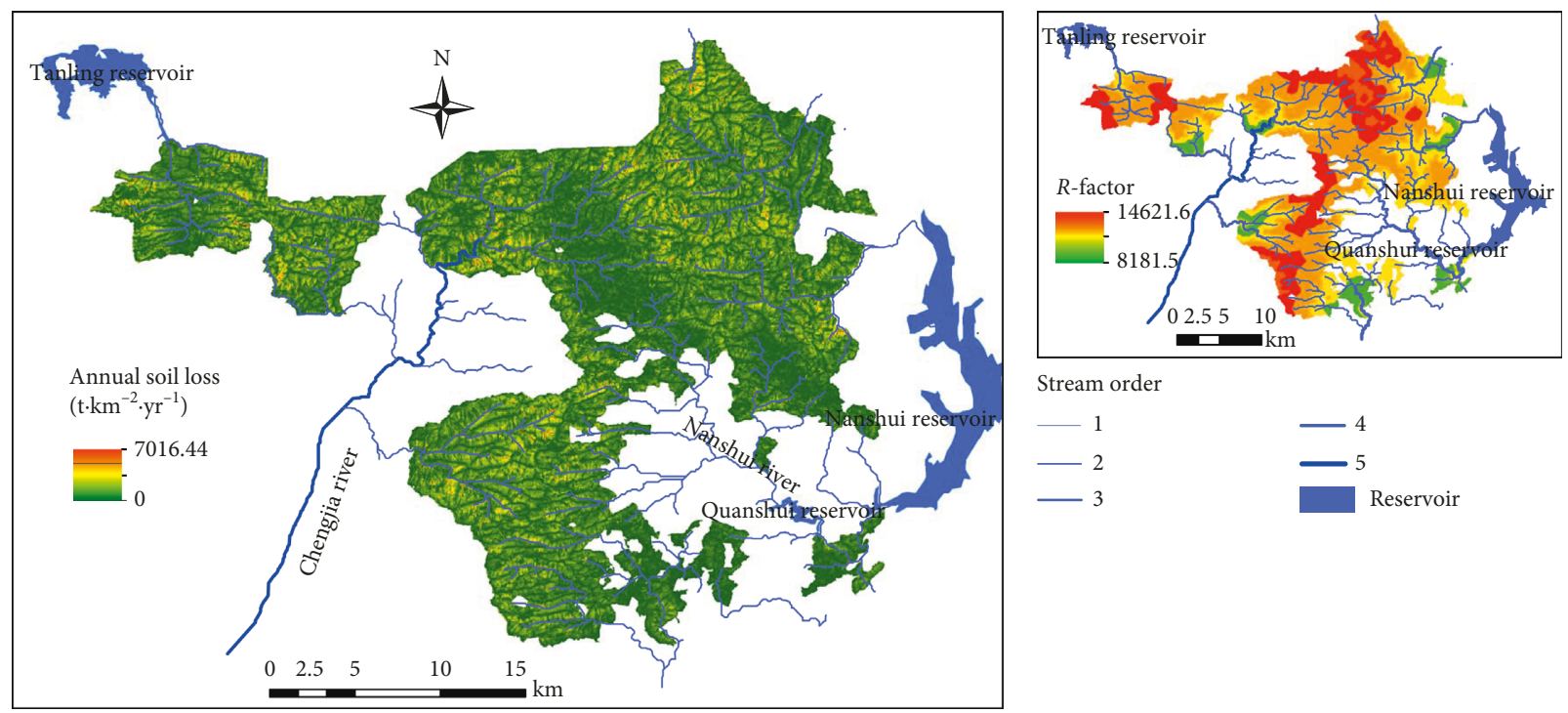

Stream order

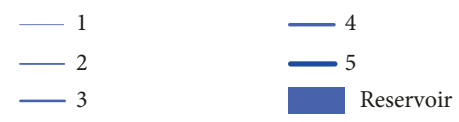

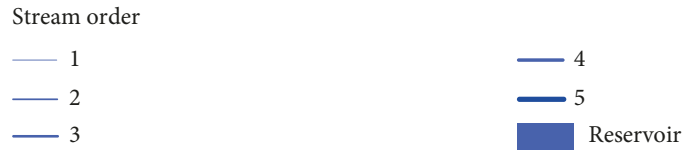

(a)

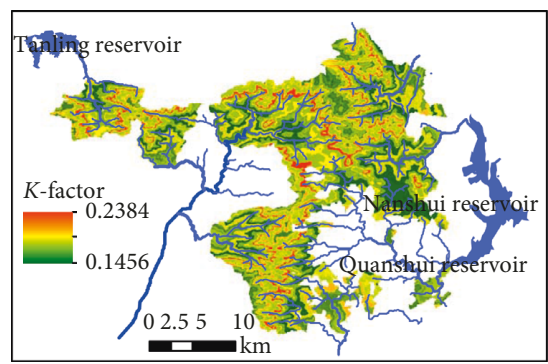

Stream order

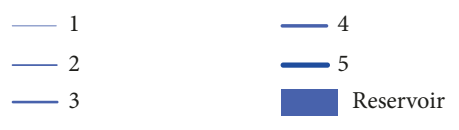

(c) (b)

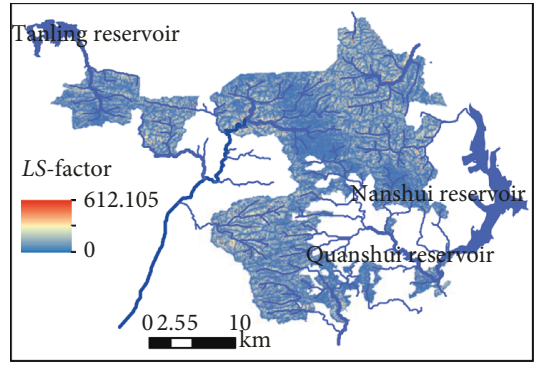

Stream order

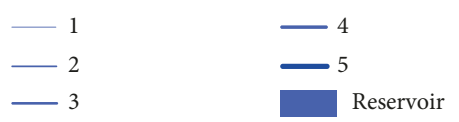

(d)
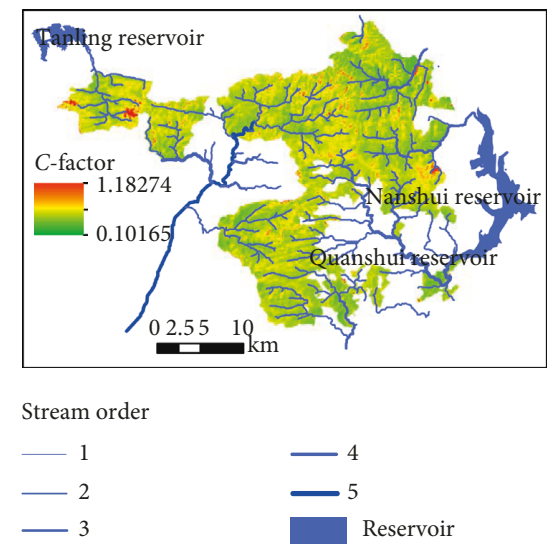

(e)

FIgURE 5: The calculated results of the RUSLE model and its input variables: (a) the calculated result of RUSLE, (b) $R$-factor, (c) $K$-factor, (d) $L S$-factor, and (e) $C$-factor. 
TABLE 1: Mean monthly rainfall and $R$-factor in NNNR.

\begin{tabular}{|c|c|c|c|c|c|c|c|c|c|c|c|c|c|c|}
\hline \multirow{2}{*}{ Year } & \multicolumn{12}{|c|}{ Monthly rainfall (mm) } & \multirow{2}{*}{ Annual rainfall (mm) } & \multirow{2}{*}{$R$-factor } \\
\hline & Jan. & Feb. & Mar. & Apr. & May. & Jun. & Jul. & Aug. & Sep. & Oct. & Nov. & Dec. & & \\
\hline 2008 & 127.2 & 53.4 & 156.4 & 160.0 & 148.6 & 561.6 & 214.6 & 115.1 & 142.5 & 79.3 & 79.2 & 15.7 & & 12700.9 \\
\hline 2009 & 26.4 & 12.1 & 145.4 & 176.5 & 196.1 & 294.5 & 220.6 & & 66.8 & 2.3 & 123.2 & 43.5 & & 8181.5 \\
\hline 2010 & 245.1 & 95.4 & 88.0 & 326.1 & 424.0 & 380.1 & 60.0 & 93.0 & 193.5 & 28.7 & 8.7 & 87.7 & 2030.3 & 14621.6 \\
\hline 2011 & 30.2 & 70.8 & 116.6 & 61.7 & 562.8 & 253.8 & 134.7 & 91.0 & 128.6 & 157.1 & 43.4 & 9.9 & 1660.6 & 11737.0 \\
\hline 2012 & 142.2 & 82.2 & 162.9 & 288.8 & 231.6 & 373.5 & 163.7 & 113.0 & 61.2 & 21.7 & 249.5 & 123.9 & 2014.1 & 12755.0 \\
\hline 2013 & 39.9 & 56.7 & 164.6 & 248.9 & 335.0 & 173.7 & 110.1 & 474.0 & 173.1 & 7.1 & 61.6 & 78.9 & 1923.5 & 13391.3 \\
\hline 2014 & 13.5 & 89.4 & 182.4 & 180.2 & 340.3 & 246.5 & 208.3 & 208.4 & 64.9 & 8.8 & 88.0 & 48.6 & 1679.2 & 10187.6 \\
\hline 2015 & 50.0 & 95.5 & 95.2 & 123.3 & 379.7 & 208.0 & 187.9 & 127.9 & 220.3 & 109.1 & 155.8 & 192.9 & 1945.6 & 11597.9 \\
\hline 2016 & 177.0 & 58.6 & 211.6 & 370.5 & 242.6 & 293.4 & 187.1 & 260.7 & 92.4 & 104.0 & 125.1 & 31.5 & 2154.5 & 14009.1 \\
\hline
\end{tabular}

TABLE 2: The property and $K$-factors of 32 soil field samples in the study area.

\begin{tabular}{|c|c|c|c|c|c|c|c|}
\hline No. & Slope $\left({ }^{\circ}\right)$ & Elevation (m) & $\begin{array}{c}m_{\mathrm{c}}(\%) \\
<0.002 \mathrm{~mm}\end{array}$ & $\begin{array}{c}m_{\text {silt }}(\%) \\
0.002-0.05 \mathrm{~mm}\end{array}$ & $\begin{array}{c}m_{\mathrm{s}}(\%) \\
0.05-2.0 \mathrm{~mm}\end{array}$ & $\operatorname{org} C(\%)$ & $K$ \\
\hline S4 & 41 & 413 & 2.9333 & 69.7600 & 27.3167 & 2.30 & 0.1761 \\
\hline S5 & 30 & 522 & 16.4967 & 42.6367 & 40.8567 & 0.78 & 0.1747 \\
\hline S6 & 59 & 604 & 7.6833 & 59.4200 & 32.8900 & 3.39 & 0.1518 \\
\hline S7 & 35 & 715 & 19.7867 & 66.5733 & 13.6267 & 2.59 & 0.2041 \\
\hline S8 & 50 & 803 & 15.7333 & 64.6200 & 19.6400 & 4.15 & 0.1761 \\
\hline S9 & 37 & 919 & 10.5100 & 55.3733 & 34.1200 & 5.35 & 0.1467 \\
\hline S10 & 37 & 1015 & 7.6933 & 62.0267 & 30.2800 & 5.15 & 0.1563 \\
\hline S11 & 34 & 1104 & 6.1333 & 68.6067 & 25.2400 & 4.32 & 0.1750 \\
\hline S12 & 26 & 1199 & 9.0133 & 76.7567 & 14.2333 & 4.76 & 0.2384 \\
\hline S13 & 13 & 1318 & 8.2167 & 71.8833 & 19.8967 & 2.78 & 0.1975 \\
\hline S14 & 30 & 1402 & 7.0033 & 74.0900 & 18.9067 & 5.77 & 0.2085 \\
\hline S15 & 35 & 1498 & 16.8000 & 64.1267 & 19.0633 & 1.94 & 0.1801 \\
\hline S16 & 40 & 1606 & 7.1567 & 65.6600 & 27.1933 & 5.21 & 0.1654 \\
\hline S17 & 34 & 1696 & 9.0667 & 65.8933 & 25.0200 & 2.47 & 0.1693 \\
\hline S18 & 26 & 1795 & 8.7233 & 61.3367 & 29.9433 & 3.26 & 0.1553 \\
\hline S19 & 37 & 1897 & 8.5533 & 67.4200 & 24.0233 & 5.18 & 0.1740 \\
\hline N5 & 41.00 & 503 & 8.7700 & 46.1033 & 45.0933 & 1.22 & 0.1656 \\
\hline N6 & 38.00 & 605 & 15.5033 & 58.3100 & 26.1967 & 1.54 & 0.1638 \\
\hline N7 & 34.00 & 700 & 12.5733 & 62.3433 & 25.0833 & 1.82 & 0.1661 \\
\hline N8 & 45.00 & 805 & 12.7667 & 67.8833 & 19.3367 & 1.87 & 0.1911 \\
\hline N9 & 30.00 & 900 & 4.2667 & 38.1833 & 57.3467 & 2.04 & 0.1470 \\
\hline N10 & 34.00 & 1014 & 5.2667 & 70.7800 & 23.8967 & 4.41 & 0.1837 \\
\hline N11 & 10.00 & 1087 & 6.8167 & 71.2900 & 21.8933 & 3.72 & 0.1898 \\
\hline N12 & 34.00 & 1210 & 7.9433 & 68.3933 & 23.6567 & 3.56 & 0.1773 \\
\hline N13 & 18.00 & 1317 & 4.0467 & 66.2133 & 29.7467 & 3.49 & 0.1642 \\
\hline N14 & 40.00 & 1415 & 9.8967 & 61.1033 & 28.9867 & 2.98 & 0.1555 \\
\hline N15 & 25.00 & 1503 & 7.0100 & 65.9300 & 27.0633 & 3.74 & 0.1661 \\
\hline N16 & 28.00 & 1594 & 4.4667 & 61.5433 & 33.9867 & 2.84 & 0.1548 \\
\hline N17 & 30.00 & 1700 & 7.0200 & 51.6200 & 41.3600 & 7.87 & 0.1456 \\
\hline N16 & 30.00 & 1603 & 5.2167 & 53.3567 & 41.4267 & 3.04 & 0.1475 \\
\hline N17 & 41.00 & 1707 & 5.6367 & 50.8400 & 43.5133 & 3.68 & 0.1462 \\
\hline N18 & 36.00 & 1812 & 14.2767 & 63.7633 & 21.6233 & 4.94 & 0.1697 \\
\hline
\end{tabular}

TABLE 3: The area and percentage of calculated $L S$-factor in the study.

\begin{tabular}{lccc}
\hline$L S$ & $L S<100$ & $100<L S<200$ & $L S>200$ \\
\hline Area $\left(\mathrm{km}^{2}\right)$ & 383.83 & 145.96 & 53.90 \\
Percentage (\%) & $65.76 \%$ & 25.01 & 9.23 \\
\hline
\end{tabular}

in the first-order river. The high $L S$-factor value mainly lies in the mountainous area which has steep terrain and ridge line, especially in the Ruyang section. The $L S$-factor could be classified into three classes: $65.76 \%\left(383.83 \mathrm{~km}^{2}\right)$ of the area was under 100. LS values between 100 and 200 accounted for $25.01 \%\left(145.96 \mathrm{~km}^{2}\right)$. LS value $>300$ accounted for $9.23 \%$ $\left(53.90 \mathrm{~km}^{2}\right)$ of the area (Table 3$)$. The value of the normalized difference vegetation index of the NNNR was between -0.092 and 0.533 , and the computed $C$-factor was in the range 0.1017-1.1827 (Figure 5(e)).

The calculated longtime average annual soil loss in NNNR by the RUSLE model is shown in Figure 5(a). The result showed that the range of calculated longtime average 
annual soil loss in NNNR was between 0.0 and $7016.44 t$ $\mathrm{km}^{-2} \cdot \mathrm{yr}^{-1}$, with an average value of $137.68 t \mathrm{~km}^{-2} \cdot \mathrm{yr}^{-1}$. In accordance with the criteria of soil erosion intensity issued by the Ministry of Water Resources, China, which was determined mainly based on field experiments in China and it was guaranteed applicable for all China [46], the calculated results were classified into six categories: negligible, slight, moderate, severe, very severe, and extremely severe (Table 4).

From Table 4, we could observe that approximately $90.17 \%$ of the area in the NNNR had negligible erosion loss currently, while none area had very severe or extremely severe erosion and only $0.25 \%$ showed severe erosion loss.

3.2. Interpretation Results and Ground Truth Checking of RUSLE. The overall soil erosion area is about $11.91 \mathrm{~km}^{2}$, accounting for $2.1 \%$ of the study area (Figure 6). According to our fieldworks in NNNR, rill erosion is mainly distributed upstream of the slope, which is relatively discrete and does not form a certain shape, gully erosion is derived from rill erosion and generally connected to the main ditch, forming a strip-like shape, sheet erosion is developed around mountain ridge lines and is distributed in a sheet shape, and humaninduced erosion is mainly distributed within the human activity, such as roads and scenic spots. Therefore, based on the terrain slope, geometric shape, and human activity range, the distribution of four types of soil erosion can be further subdivided. The result is that the rill, sheet, gully, and human-induced erosion account for $12.9 \%, 23.9 \%, 16.5 \%$, and $46.7 \%$ of the land, respectively, seen in Table 5 . The soil erosion types of 32 samples along the elevation gradient in NNNR were identified by the filed investigation. The result showed that the interpreted soil erosion type of 26 in 32 samples is consistent with the field survey results indicating that the error introduced by the interpretation was acceptable. Besides, The soil erosion types of five UAV survey samples were identified by indoor visual interpretation were also used to validate this interpreted result which showed that the error was also acceptable. The validated samples are shown in Figure 7. Therefore, the interpreted result can be used as the actual distribution of soil erosion in NNNR.

After verification of the interpreted results of remote sensing images, we performed ground truth checking of the RUSLE and assessed its performance in application to the NNNR. We first performed a spatial overlay analysis between the RUSLE and interpreted results in ArcGIS 10.1, and we calculated the areas of the four types of soil erosion in the six erosion categories. The result shows that $93.85 \%, 6.02 \%$, and $0.13 \%$ of the soil erosion was classified as negligible, slight, and moderate, respectively, while none was classified as severe, very severe, or extremely severe. It has obvious difference of soil loss class between RUSLE results and the actual situation in NNNR. We then further compared the spatial distributions of the RUSLE results and the actual situation of soil erosion within the NNNR. It was found that despite the overlap in the ranges of the RUSLE results and the actual situation, significant differences between the two spatial distributions were apparent. We considered two examples to illustrate this problem
TABle 4: Categories of soil erosion class and the area and proportion of each category.

\begin{tabular}{lcccc}
\hline $\begin{array}{l}\text { Soil } \\
\text { loss } \\
\text { class }\end{array}$ & Intensity & $\begin{array}{c}\text { Annual mean erosion } \\
\text { modulus }\left(\mathrm{t} \mathrm{km}^{-2} \cdot \mathrm{yr}^{-1}\right)\end{array}$ & $\begin{array}{c}\text { Area } \\
\left(\mathrm{km}^{2}\right)\end{array}$ & $\begin{array}{c}\text { Proportion } \\
(\%)\end{array}$ \\
\hline 1 & Negligible & $<500^{\mathrm{a}}(1000)$ & 526.31 & 90.17 \\
2 & Slight & $<500^{\mathrm{a}}(1000)-2500$ & 39.69 & 6.80 \\
3 & Moderate & $2500-5000$ & 16.21 & 2.78 \\
4 & Severe & $5000-10,000$ & 1.46 & 0.25 \\
5 & Very & $10,000-15,000$ & 0.00 & 0.00 \\
& severe & & & \\
& Extremely & $>15,000$ & 0.00 & 0.00 \\
\hline
\end{tabular}

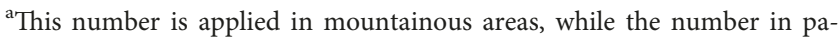
rentheses is applied in other areas [46].

(Figure 7): First, for Site A, Figure 7(a) shows the RUSLE result and Figure 7(b) shows the actual condition of human-induced erosion in Ruyang section in NNNR. It is evident that the spatial distribution of soil loss has considerable difference between the RUSLE result and actual situation in NNNR. Second, for Site B, Figure 7(c) shows the slight, moderate, and severe classes derived from the RUSLE and Figure 7(d) shows the actual conditions of the corresponding site, which has good vegetation coverage and no soil erosion actually. Clearly, the categorization of this area as slight, moderate, and severe classes by the RUSLE is unreasonable with regard to actual situation in terms of soil loss class and spatial distribution.

The above ground truth checking indicates the spatial distributions and soil loss classes derived from the RUSLE, both have considerable differences compared with the actual situation. Thus, the performance of the RUSLE is not satisfactory, and it could produce such differences when used to estimate the ecological risks posed by soil erosion in NNNR, which is an area of complex topography manifested as steep slopes and ravines, where intense tourism development has occurred. The application of the RUSLE in such a region warrants greater attention and further discussion. Soil erosion in the NNNR is extremely complex and controlled by various factors, except the factors within the RUSLE. Therefore, it is very important to understand the key underlying factors that influence soil erosion prior to erosion modelling.

3.3. Analysis of Key Influencing Factors. The areas of each type of soil erosion according to the interpreted results of soil erosion are listed in Table 2 . The area of the NNNR is $583.68 \mathrm{~km}^{2}$; thus, the values of $P_{\mathrm{S}}$ for soil erosion types 1-4, calculated using equation (7), were 0.0026, 0.0049, 0.0034, and 0.0095 , respectively. The classified data classes of each influencing factor and certainty coefficient values of each data class $\left(\mathrm{CF}_{i}\right)$ are listed in Table 6 .

According to Table 6, rill erosion is very serious in areas with an $L S$ value $>200$, elevation $<400 \mathrm{~m}$, flat aspect, $R$ value of $12474.5-14621.6 \mathrm{MJ} \mathrm{mm} \cdot \mathrm{ha}^{-1} \cdot \mathrm{h}^{-1} \cdot \mathrm{yr}^{-1}$, distance to drainage networks of 300-400 $\mathrm{m}$, and $C$ value of $0.449-1.181$. The slope pattern, $K$ value, lithology, and wind speed are not the key influencing factors for rill erosion, for which the 


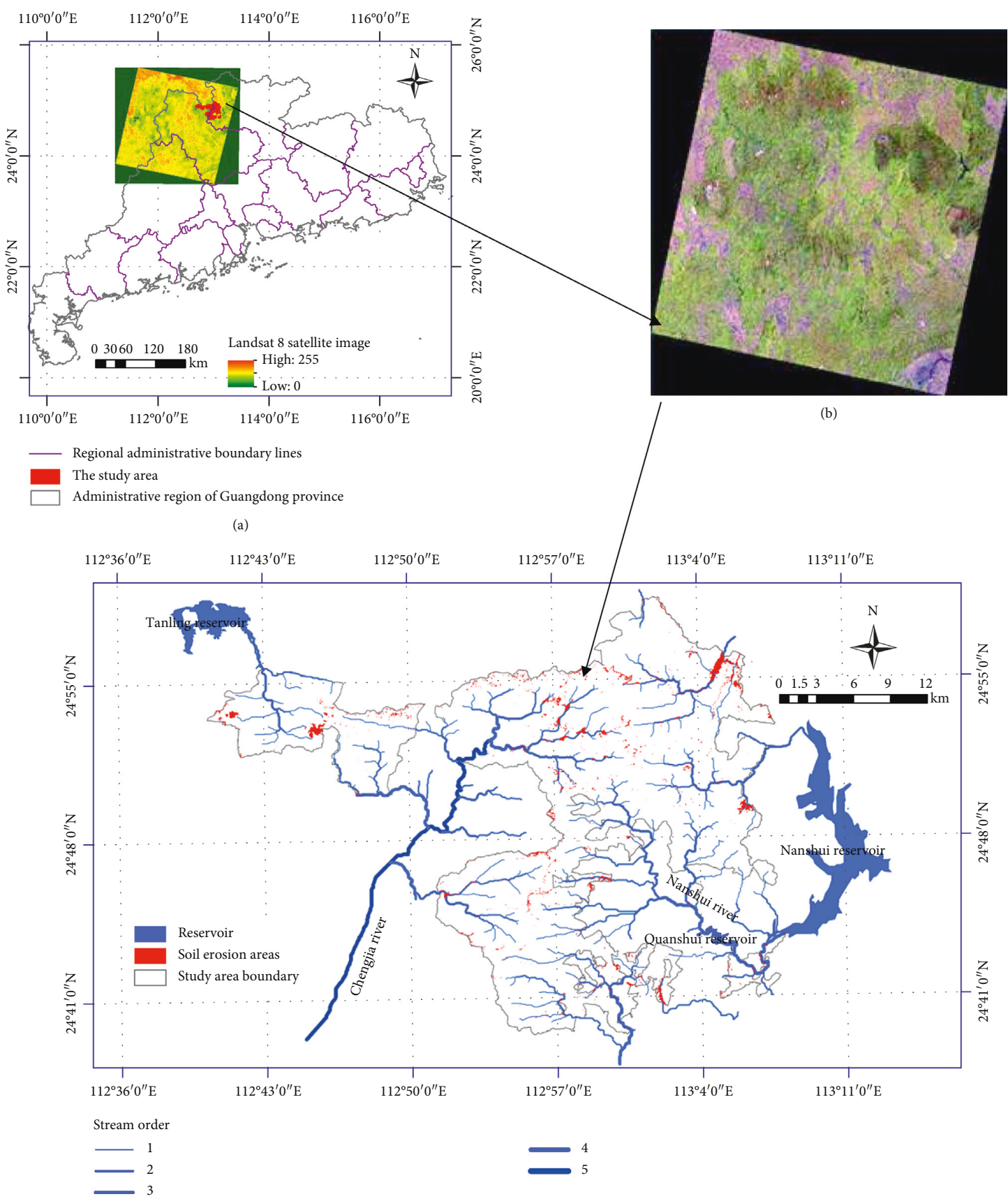

(c)

Figure 6: The Landsat 8 remote sensing image and the soil erosion distribution in NNNR: (a) The location map of Landsat 8 remote sensing image, (b) the Landsat 8 image, and (c) the distribution of soil erosion in NNNR. This figure is reproduced from Wang et al. [28] (under the Creative Commons Attribution License/public domain).

TABLE 5: Areas of the interpreted four types of soil erosion in NNNR.

\begin{tabular}{lccccc}
\hline & \multicolumn{5}{c}{ The area of four types soil erosion $\left(\mathrm{km}^{2}\right)$} \\
$\begin{array}{l}\text { Soil loss } \\
\text { class }\end{array}$ & $\begin{array}{c}\text { Rill } \\
\text { erosion }\end{array}$ & $\begin{array}{c}\text { Sheet } \\
\text { erosion }\end{array}$ & $\begin{array}{c}\text { Gully } \\
\text { erosion }\end{array}$ & $\begin{array}{c}\text { Human- } \\
\text { induced } \\
\text { erosion }\end{array}$ & Total \\
\hline $\begin{array}{l}\text { Area }\left(\mathrm{km}^{2}\right) \\
\begin{array}{l}\text { Proportion } \\
(\%)\end{array}\end{array}$ & 1.534 & 2.841 & 1.969 & 5.561 & 11.905 \\
\hline
\end{tabular}

calculated CF values are close to or less than zero. The factors of $L S$, elevation, aspect, and $C$ have greater impact than other factors on rill erosion. The probability of sheet erosion is very high with an elevation of 1000-1300 m, south aspect, convex slope pattern, $K$ value of $0.207-0.238 t$ ha h $\cdot \mathrm{ha}^{-1} \cdot \mathrm{MJ}^{-1} \cdot \mathrm{mm}^{-1}$, $R$ value of $12474.5-14621.6 \mathrm{MJ} \mathrm{mm} \cdot \mathrm{ha}^{-1} \cdot \mathrm{h}^{-1} \cdot \mathrm{yr}^{-1}$, distance to drainage networks of 300-400 $\mathrm{m}, 10-\mathrm{min}$ maximum wind speed of $2.85-5.13 \mathrm{~m} \cdot \mathrm{s}^{-1}$, and $C$ value of $0.339-0.449$. Therefore, elevation, aspect, slope pattern, $K, R$, distance to drainage networks, and $C$ are the key factors influencing 

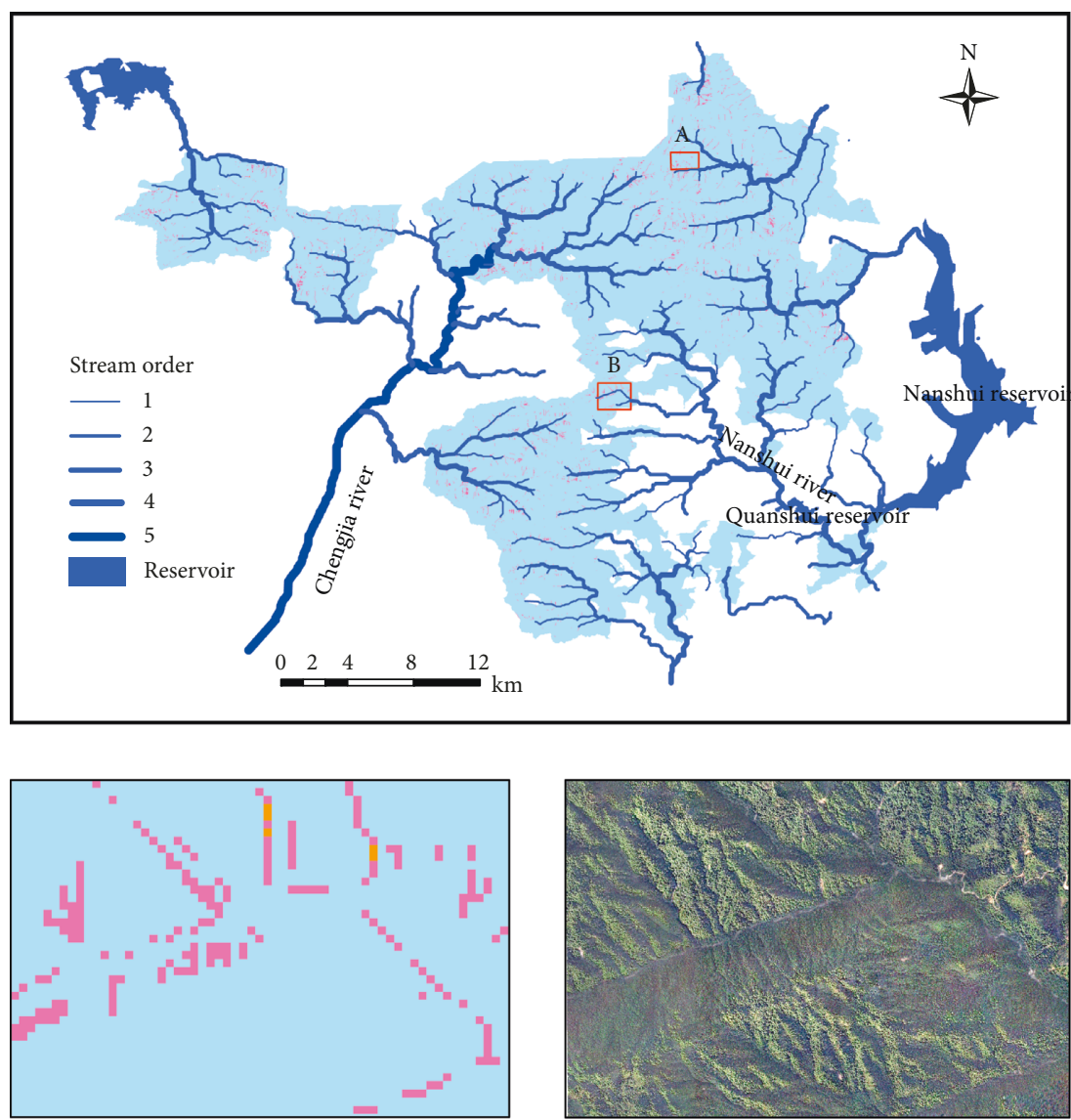

(c)

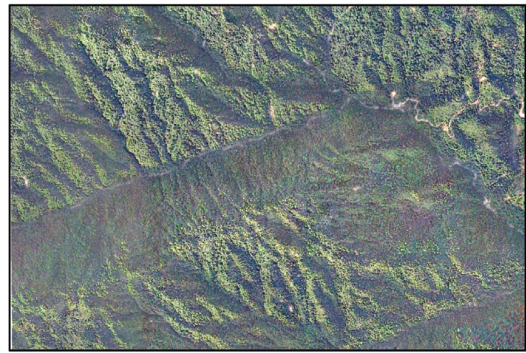

(d)

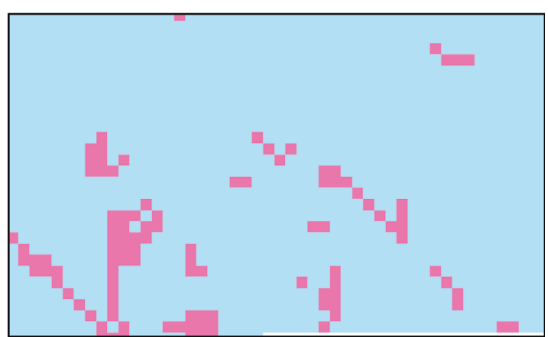

(a)

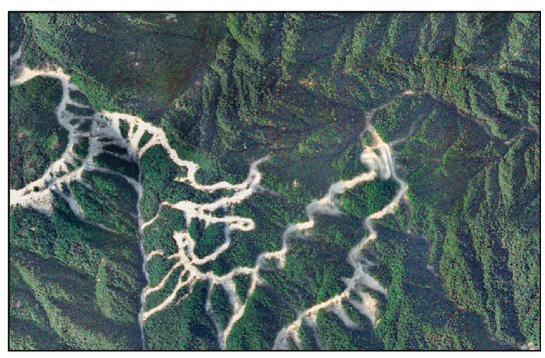

(b)

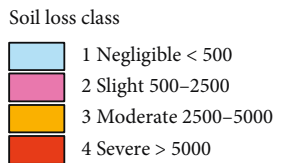

FIgURE 7: The comparison between the result derived from RUSLE and the remote sensing images: (a) RUSLE result of site A; (b) the remote sensing image of site A; (c) RUSLE result of site B; and (d) the remote sensing image of site B.

sheet erosion within the NNNR. Moreover, the factors of $R$, distance to drainage networks, and $C$ have greater impact than other factors on sheet erosion. Gully erosion is very serious in areas with an $L S$ value $>200$, elevation of $<400 \mathrm{~m}$, flat aspect, concave slope pattern, $K$ value of $0.146-0.177 t$ ha $\mathrm{h} \cdot \mathrm{ha}^{-1} \cdot \mathrm{MJ}^{-1} \cdot \mathrm{mm}^{-1}$, Devonian lithology, $R$ value of $8181.5-$ $10328 \mathrm{MJ} \mathrm{mm} \cdot \mathrm{ha}^{-1} \cdot \mathrm{h}^{-1} \cdot \mathrm{yr}^{-1}$, distance to drainage networks of $<100 \mathrm{~m}$, and $C$ value of $0.449-1.181$. The $L S$, elevation, aspect, distance to drainage networks, and $C$ have the greater impact than other factors on gully erosion. The probability of human-induced erosion is high with an $L S$ value $>200$, elevation of $400-700 \mathrm{~m}$, flat aspect, flat slope pattern, $K$ value of $0.146-0.177 t$ ha $h \cdot \mathrm{ha}^{-1} \cdot \mathrm{MJ}^{-1} \cdot \mathrm{mm}^{-1}$, Carboniferous lithology, $R$ value of $8181.5-10328 \mathrm{MJ} \mathrm{mm} \cdot \mathrm{ha}^{-1} \cdot \mathrm{h}^{-1} \cdot \mathrm{yr}^{-1}$, distance to drainage networks of $<100 \mathrm{~m}$, wind speed of $5.13-7.41 \mathrm{~m} \cdot \mathrm{s}^{-1}$, and $C$ value of $0.449-1.182$. Among these factors, $L S$, elevation, aspect, lithology, $R$, distance to drainage networks, and $C$ have greater impact than other factors on human-induced erosion.

For each underlying influencing factor, the influence degree on different types of soil erosion was also found significantly different (Table 7). The factors of $L S$, elevation, and aspect have strong impact on rill, gully, and humaninduced erosion and they have similar variation trends. The slope pattern is very important for sheet and human- induced erosion. Sheet erosion occurs mainly on convex slopes, whereas human-induced erosion occurs mainly on flat slopes. Lithology is also a very important factor in relation to human-induced erosion. If lithology is not considered, the risk of human-induced erosion might be underestimated because lithology is closely related to rock and soil movements, e.g., mudslides and landslides. The $K$ factor and wind speed have less influence than other factors on soil erosion within the NNNR. The distance to drainage networks is a key factor that has strong influence on all types of soil erosion where the drainage network is relatively developed. The $C$-factor also has substantial impact on all types of soil erosion; in fact, it is the decisive factor controlling soil erosion.

According to the above analysis, the influence degree of each factor data class on different types of soil erosion in the NNNR can be shown in Table 7. The results also reveal areas of possible high risk arising from the four types of soil erosion. Thus, it should be possible to determine appropriate countermeasures to restrict this development in such areas.

Based on the above analysis, we can come to the conclusion that the reason for generating the differences derived from the RUSLE is that different soil erosion types in NNNR had quite different influencing factors, and the RUSLE could not express these differential factors with its own factors. 


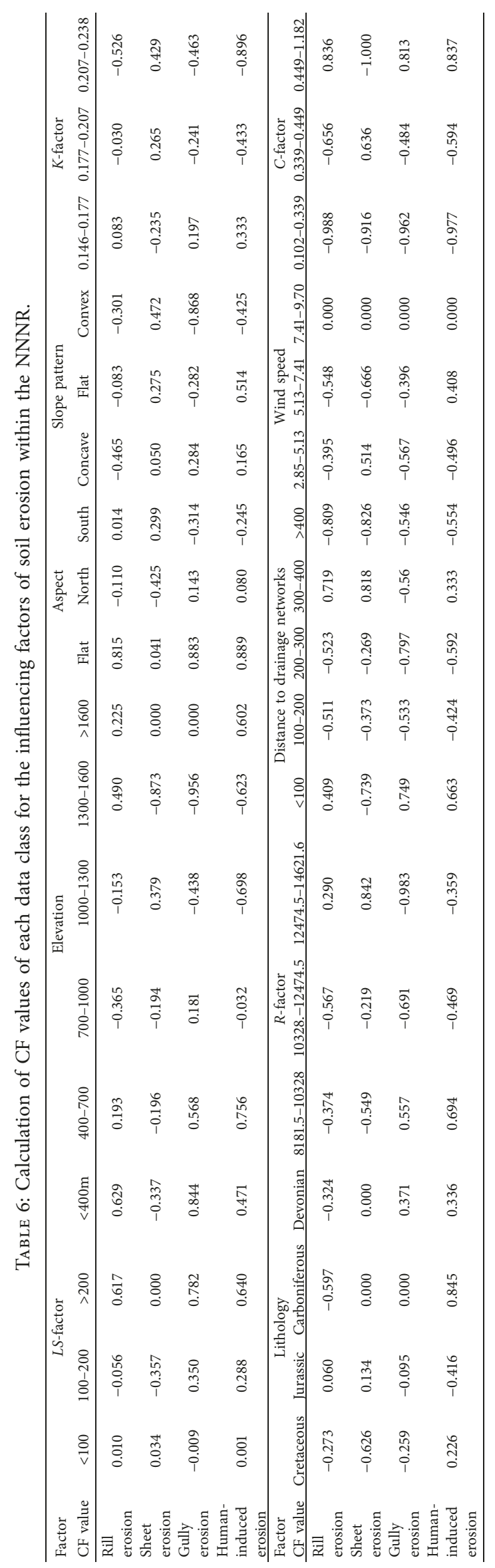


TABLE 7: Influence degree of each factor on four types of soil erosion within the NNNR.

\begin{tabular}{|c|c|c|c|c|c|c|c|c|c|c|}
\hline \multirow[b]{2}{*}{ Erosion types } & \multicolumn{10}{|c|}{ The key influencing factors } \\
\hline & $L S$ & Elevation & Aspect & $\begin{array}{l}\text { Slope } \\
\text { pattern }\end{array}$ & K & Lithology & $R$ & $\begin{array}{c}\text { Distance to drainage } \\
\text { net }\end{array}$ & $\begin{array}{l}\text { Wind } \\
\text { speed }\end{array}$ & $C$ \\
\hline a. Rill erosion & $* * * *$ & $* * * *$ & $* * * *$ & $*$ & $*$ & * & $* *$ & $* * *$ & $*$ & $* * * *$ \\
\hline b. Sheet erosion & $*$ & $* *$ & $* *$ & $* * *$ & $* * *$ & $*$ & $* * * *$ & $* * * *$ & $* * *$ & $* * * *$ \\
\hline $\begin{array}{l}\text { c. Gully erosion } \\
\text { d. Human-induced }\end{array}$ & $* * * *$ & $* * * *$ & $* * * *$ & $* *$ & $*$ & $* *$ & $* * *$ & $* * * *$ & $*$ & $* * * *$ \\
\hline $\begin{array}{l}\text { d. Human-1nduced } \\
\text { erosion }\end{array}$ & $* * * *$ & $* * * *$ & $* * * *$ & $* * *$ & $* *$ & $* * * *$ & $* * * *$ & $* * * *$ & $* * *$ & $* * * *$ \\
\hline
\end{tabular}

The asterisk refers to the influence degree of each factor on different types of soil erosion. For a CF value of $<0.2$, the probability of soil erosion and its influence degree is low $(*)$; for a CF value of $0.2-0.4$, the probability of soil erosion and its influence degree is moderate $(* *)$; for a CF value of $0.4-0.6$, the probability of soil erosion and its influence degree is high $(* * *)$; and for a CF value $>0.6$, the probability of soil erosion and its influence degree is very high $(* * * *)$.

Therefore, we suggest the following: (i) the soil erosion type and the key underlying factor influencing each type of soil erosion should be determined prior to erosion modelling, (ii) ground truth checking and the performance of the RUSLE should be tested before implementing any water and soil conservation practices, and, if necessary, the RUSLE should be revised according to its key influencing factors, and (iii) in future soil erosion studies, for reasonable assessment of soil erosion, different erosion models should be established for different types of soil erosion, rather than using a single model for an approximate assessment of all types of soil erosion in a watershed.

\section{Conclusions}

This study produced a soil erosion risk map with predicted factors by integrating the RUSLE and GIS data, and tested the performance of the RUSLE via ground truth checking. Innovatively, a probability method was proposed to analyze the occurrence possibility of soil erosion and to elucidate the relationships between four types of soil erosion and the key influencing factors. The results showed substantial differences both in the spatial distribution and soil loss class between the RUSLE and the actual situation. The performance of the RUSLE was not satisfactory because it could produce differences or even errors when used to estimate the ecological risks posed by soil erosion within the NNNR, a region with steep slopes, complex topography, and intense anthropogenic activity. The key influencing factors, such as elevation, aspect, slope pattern, lithology, distance to drainage net, and wind speed as well as RUSLE factors, were selected to analyze their influence degree on different soil erosion types.

The result showed that the influence degree of each factor on different types of soil erosion varied markedly. Moreover, the different types of soil erosion were found to have different key influencing factors. The reason for generating the differences derived from the RUSLE is that different soil erosion types in NNNR had quite different influencing factors, and the RUSLE could not express these differential factors with its factors. The results also revealed the variables with disadvantageous effects on soil erosion, and the region has high soil erosion risk. According to such findings, it should be possible to implement appropriate countermeasures to restrict such development in certain areas. In the future studies, we would revise the traditional RUSLE according to the key influencing factors of different types of soil erosion to obtain a map of soil erosion risk within the NNNR that is more reasonable.

\section{Data Availability}

The data used to support the findings of this study are available from the corresponding author upon request.

\section{Conflicts of Interest}

The authors declare that there are no conflicts of interest regarding the publication of this paper.

\section{Acknowledgments}

The authors thank Meili Wen, Long Yang, and Zhongyu Sun for their efforts and help in field investigation, data curation, and laboratory experiments. We also would like to thank Editage (http://www.editage.cn) for English language editing. This research was supported by the CRSRI Open Research Program (Program SN: CKWV2017524/KY), Guangdong Provincial Science and Technology Program (2018B030324001), GDAS' Special Project of Science and Technology Development (2019GDASYL-0401001, 2017GDASCX-0701, 2018GDASCX-0101, and 2017GDASCX-0807), Guangzhou Science and Technology Project (201804010126 and 201803030025), Natural Science Foundation of Guangdong Province (2018A030310469), Water Resource Science and Technology Innovation Program of Guangdong Province (2016-15), and National Natural Science Foundation of China (41671506).

\section{References}

[1] P. Zhou, O. Luukkanen, T. Tokola, and J. Nieminen, "Effect of vegetation cover on soil erosion in a mountainous watershed," CATENA, vol. 75, no. 3, pp. 319-325, 2008.

[2] A. Adediji, A. M. Tukur, and K. A. Adepoju, "Assessment of revised universal soil loss equation (RUSLE) in Katsina area, Katsina State of Nigeria using remote sensing (RS) and geographic information system (GIS)," Iranica Journal of Energy \& Environment, vol. 1, pp. 255-264, 2010.

[3] A. Sharma, "Integrating terrain and vegetation indices for identifying potential soil erosion risk area," Geo-Spatial Information Science, vol. 13, no. 3, pp. 201-209, 2010. 
[4] W. M. Soohoo, C. Wang, and H. Li, "Geospatial assessment of bioenergy land use and its impacts on soil erosion in the U.S. Midwest," Journal of Environmental Management, vol. 190, no. 1, pp. 188-196, 2017.

[5] Z. X. Zeng, "Soil erosion on the red soil regions in South China," Pearl River, vol. 6, pp. 15-20, 1992, in Chinese.

[6] R. Lal, "Soil degradation by erosion," Land Degradation \& Development, vol. 12, no. 6, pp. 519-539, 2001.

[7] A. Lufafa, M. M. Tenywa, M. Isabirye, M. J. G. Majaliwa, and P. L. Woomer, "Prediction of soil erosion in a Lake Victoria basin catchment using a GIS-based universal soil loss model," Agricultural Systems, vol. 76, no. 3, pp. 883894, 2003.

[8] R. B. Kiunsi and M. E. Meadows, "Assessing land degradation in the Monduli District, Northern Tanzania," Land Degradation \& Development, vol. 17, no. 5, pp. 509-525, 2006.

[9] P. J. Ligonja and R. P. Shrestha, "Soil erosion assessment in Kondoa eroded area in Tanzania using universal soil loss equation, geographic information systems and socioeconomic approach," Land Degradation \& Development, vol. 26, no. 4, pp. 367-379, 2015.

[10] W. S. Merritt, R. A. Letcher, and A. J. Jakeman, "A review of erosion and sediment transport models," Environmental Modelling \& Software, vol. 18, no. 8-9, pp. 761-799, 2003.

[11] J. Thomas, S. Joseph, and K. P. Thrivikramji, “Assessment of soil erosion in a tropical mountain river basin of the Southern Western Ghats, India using RUSLE and GIS," Geoscience Frontiers, vol. 9, no. 3, pp. 893-906, 2017.

[12] R. Wang, S. Zhang, J. Yang et al., "Integrated use of GCM, RS, and GIS for the assessment of hillslope and gully erosion in the Mushi River sub-catchment, Northeast China," Sustainability, vol. 8, no. 4, pp. 409-420, 2016.

[13] M. Kouli, P. Soupios, and F. Vallianatos, "Soil erosion prediction using the revised universal soil loss equation (RUSLE) in a GIS framework, Chania, Northwestern Crete, Greece," Environmental Geology, vol. 57, no. 3, pp. 483-497, 2009.

[14] P. Plangoen, M. Babel, R. Clemente, S. Shrestha, and N. Tripathi, "Simulating the impact of future land use and climate change on soil erosion and deposition in the Mae Nam Nan sub-catchment, Thailand," Sustainability, vol. 5, no. 8, pp. 3244-3274, 2013.

[15] M. Zhu, "Soil erosion assessment using USLE in the GIS environment: a case study in the Danjiangkou Reservoir region, China," Environmental Earth Sciences, vol. 73, no. 12, pp. 7899-7908, 2015.

[16] Y. Ostovari, S. Ghorbani-Dashtaki, H.-A. Bahrami, M. Naderi, and J. A. M. Dematte, "Soil loss estimation using RUSLE model, GIS and remote sensing techniques: a case study from the Dembecha Watershed, Northwestern Ethiopia," Geoderma Regional, vol. 11, no. 2, pp. 28-36, 2017.

[17] K. Uddin, M. Abdul Matin, and S. Maharjan, "Assessment of land cover change and its impact on changes in soil erosion risk in Nepal," Sustainability, vol. 10, no. 12, pp. 4715-4726, 2018.

[18] C. M. Fayas, N. S. Abeysingha, K. G. S. Nirmanee, D. Samaratunga, and A. Mallawatantri, "Soil loss estimation using rusle model to prioritize erosion control in KELANI river basin in Sri Lanka," International Soil and Water Conservation Research, vol. 7, no. 2, pp. 130-137, 2019.

[19] P. Panagos, P. Borrelli, J. Poesen et al., "The new assessment of soil loss by water erosion in Europe," Environmental Science \& Policy, vol. 54, pp. 438-447, 2015.

[20] M. Zerihun, M. S. Mohammedyasin, D. Sewnet, A. A. Adem, and M. Lakew, "Assessment of soil erosion using RUSLE, GIS and remote sensing in NW Ethiopia," Geoderma Regional, vol. 12, pp. 83-90, 2018.

[21] A. Vrieling, G. Sterk, and O. Vigiak, "Spatial evaluation of soil erosion risk in the West Usambara Mountains, Tanzania," Land Degradation \& Development, vol. 17, no. 3, pp. 301-319, 2010.

[22] M. J. Butt, Climate, Snow and Hydrology Research Group (CSHRG), A. Waqas, and R. Mahmood, "The combined effect of vegetation and soil erosion in the water resource management," Water Resources Management, vol. 24, no. 13, pp. 3701-3714, 2010.

[23] X. Wu and X. Wang, "Spatial influence of geographical factors on soil erosion in Fuyang county, China," Procedia Environmental Sciences, vol. 10, pp. 2128-2133, 2011.

[24] Q. Ma, X. Yu, G. Lü, and Q. Liu, "The changing relationship between spatial pattern of soil erosion risk and its influencing factors in Yimeng mountainous area, China 1986-2005," Environmental Earth Sciences, vol. 66, no. 5, pp. 1535-1546, 2012.

[25] P. Bohm and G. Gerold, "Pedo-hydrological and sediment responses to simulated rainfall on soils of the Konya Uplands (Turkey)," CATENA, vol. 25, no. 1-4, pp. 63-75, 1995.

[26] B. Li and Y. Tang, "The influence of human activity on soil erosion in the lower reached of the Jinsha river," Journal of Mountain Science, vol. 3, no. 3, pp. 312-327, 2012, in Chinese.

[27] E. Sachs and P. Sarah, "Combined effect of rain temperature and antecedent soil moisture on runoff and erosion on loess," CATENA, vol. 158, no. 2-3, pp. 213-218, 2017.

[28] J. Wang, Q. Gong, and Y. Yu, "Assessing the influence of environmental factors on spatial soil erosion risk based on the certainty coefficient method," Journal of Risk Analysis and Crisis Response, vol. 8, no. 3, pp. 131-141, 2018.

[29] W. Wang, "Managing soil erosion potential by integrating digital elevation models with the southern China's revised universal soil loss equation: a case study for the west lake scenic spots area of Hangzhou, China," Journal of Mountain Science, vol. 4, no. 3, pp. 237-247, 2007.

[30] D. D. Alexakis, D. G. Hadjimitsis, and A. Agapiou, "Integrated use of remote sensing, GIS and precipitation data for the assessment of soil erosion rate in the catchment area of "Yialias" in Cyprus," Atmospheric Research, vol. 131, pp. 108-124, 2013.

[31] K. G. Renard and J. R. Freimund, "Using monthly precipitation data to estimate the $R$-factor in the revised USLE," Journal of Hydrology, vol. 157, no. 1-4, pp. 287-306, 1994.

[32] J. H. Lee and J. H. Heo, "Evaluation of estimation methods for rainfall erosivity based on annual precipitation in Korea," Journal of Hydrology, vol. 409, no. 1-2, pp. 30-48, 2011.

[33] H. M. J. Arnoldus, "Methodology used to determine the maximum potential average annual soil loss due to sheet and rill erosion in Morocco," FAO Soils Bulletin, vol. 34, pp. 3948, 1977.

[34] H. M. J. Arnoldus, "An approximation of the rainfall factor in the universal soil loss equation," in Assessment of Erosion, M. de Boodt and D. Gabriels, Eds., pp. 127-132, John Wiley \& Sons, Chichester, UK, 1980.

[35] M. Wang, X. Zhang, X. Z. Wang, X. H. Wei, and H. X. Li, "Rainfall erosivity in the Lianjiang watershed in karst areas of northern Guangdong, China," Tropical Geography, vol. 36, no. 2, pp. 495-502, 2016, in Chinese.

[36] H. Blanco-Canqui and R. Lal, Principles of Soil Conservation and Management, Springer, Dordrecht, Netherlands, 2008.

[37] X. Z. Shi, D. S. Yu, and X. X. Lv, "Study on soil erodibility by using rainfall simulator in subtropics China," Journal of Soil 
and Water Conservation, vol. 9, no. 3, pp. 38-42, 1995, in Chinese.

[38] L. A. Zhu, D. Q. Li, X. G. Wei, and H. H. Zhang, "The current situation of soil erodibility $(\mathrm{K})$ value and its impact factors in Guangdong Province," Subtropical Soil and Water Conservation, vol. 19, pp. 4-7, 2007, in Chinese.

[39] J. Williams, K. Renard, and P. Dyke, "EPIC: a new method for assessing erosion's effect on soil productivity," Journal of Soil and Water Conservation, vol. 38, no. 5, pp. 381-383, 1983.

[40] J. Wang, P. Zhou, Q. H. Gong, L. Yang, M. L. Wen, and S. Q. Fu, "Study on the soil erosion sensitivity in the nanling mountains, Guangdong, using the RUSLE model," Tropical Geography, vol. 38, no. 2, pp. 347-355, 2018, in Chinese.

[41] D. Lu, G. Li, G. S. Valladares, and M. Batistella, "Mapping soil erosion risk in Rondônia, Brazilian Amazonia: using RUSLE, remote sensing and GIS," Land Degradation \& Development, vol. 15, no. 5, pp. 499-512, 2004.

[42] J. Pan and Y. Wen, "Estimation of soil erosion using RUSLE in Caijiamiao watershed, China," Natural Hazards, vol. 71, no. 3, pp. 2187-2205, 2014.

[43] A. Van Rompaey, P. Bazzoffi, R. J. A. Jones, and L. Montanarella, "Modeling sediment yields in Italian catchments," Geomorphology, vol. 65, no. 1-2, pp. 157-169, 2005.

[44] F. Karamage, C. Zhang, F. Ndayisaba et al., "Extent of cropland and related soil erosion risk in Rwanda," Sustainability, vol. 8, no. 7, pp. 609-216, 2016.

[45] C. G. Karydas, T. Sekuloska, and G. N. Silleos, "Quantification and site-specification of the support practice factor when mapping soil erosion risk associated with olive plantations in the Mediterranean island of Crete," Environmental Monitoring and Assessment, vol. 149, no. 1-4, pp. 19-28, 2009.

[46] MWR (Ministry of Water Resources, PRC), Standards for Classification and Gradation of Soil Erosion (SL190-96), China Hydraulic and Hydropower Press, Beijing, China, 1997. 


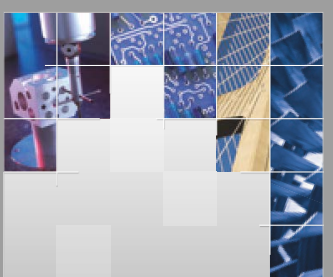

\section{Enfincering}
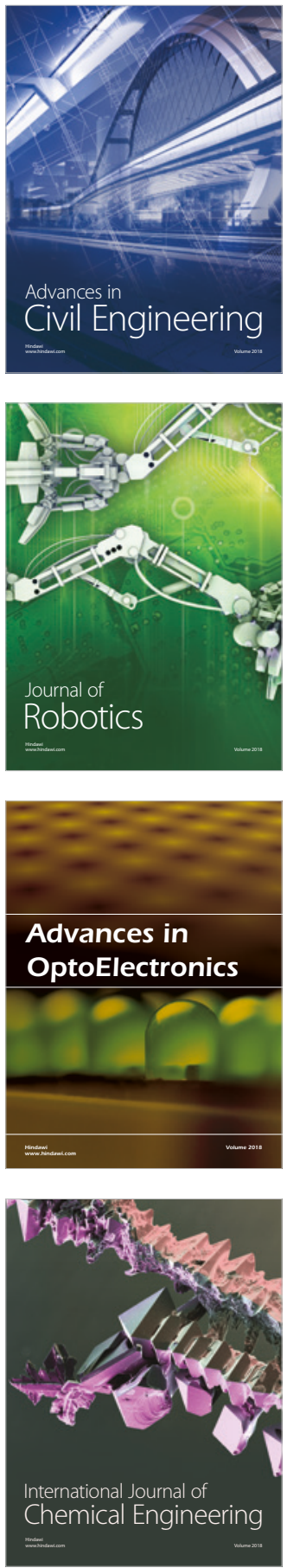

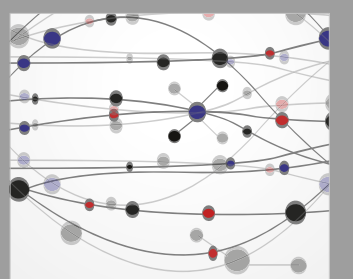

\section{Rotating \\ Machinery}

The Scientific World Journal

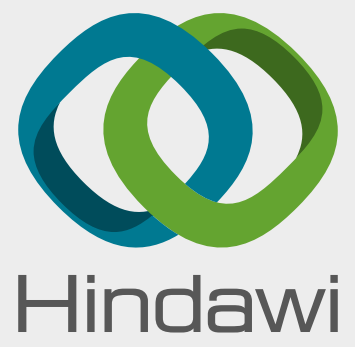

Submit your manuscripts at

www.hindawi.com
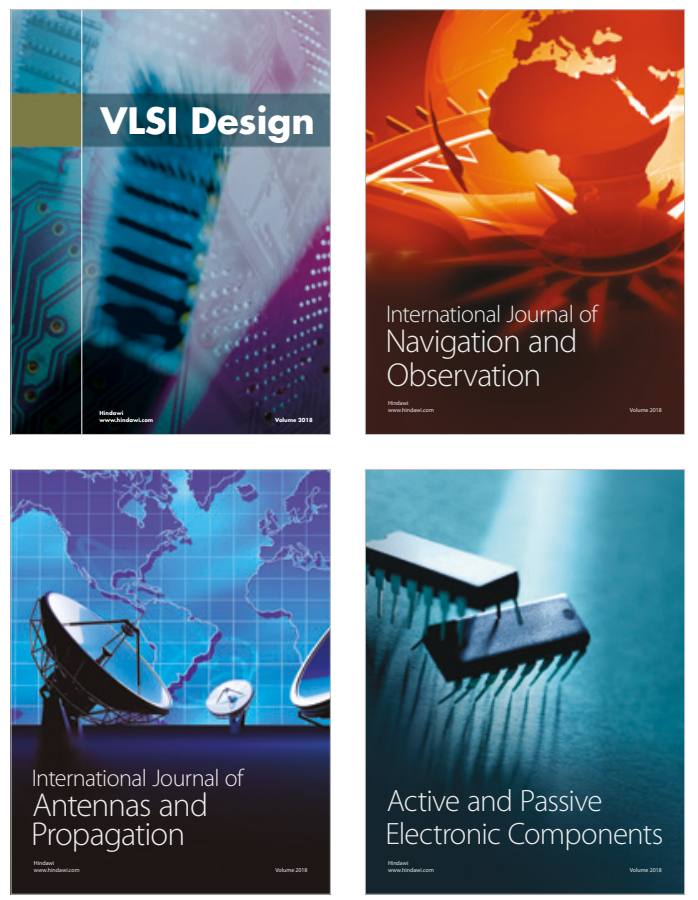
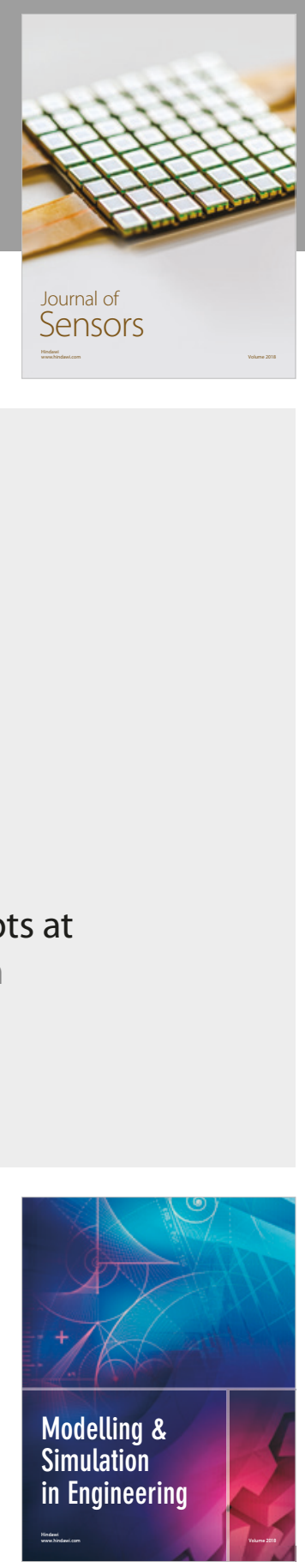

\section{Advances \\ Multimedia}
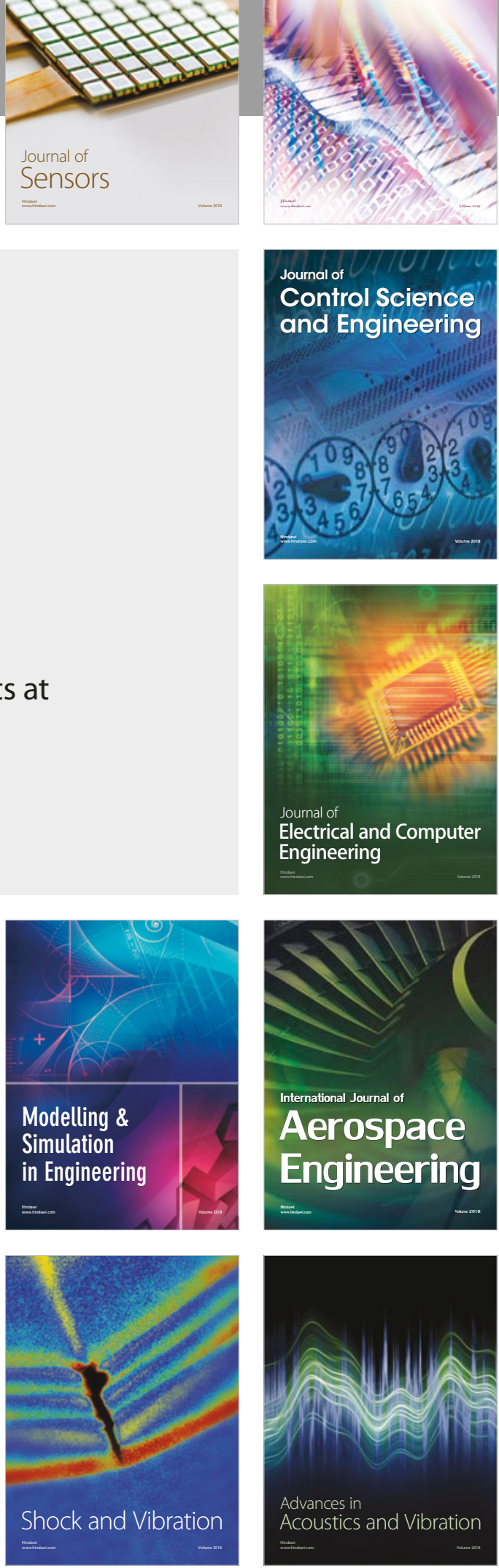